\title{
Current Strategies Involved in Biofuel Production from Plants and Algae
}

\author{
Sameera $\mathbf{V}^{1 *}$, Sameera Chenna ${ }^{2}$, Ravi Teja $\mathrm{Y}^{3}$
}

${ }^{1}$ Biotechnology Department, REVA Institute of Science and Technology, Bangalore University, India.

${ }^{2}$ Dept of Biotechnology, SVKP \& Dr. K.S.Raju Arts and Science College, Andhra University, India

${ }^{3}$ Department of Biochemistry, Dr.L.Bullayya P.G.College, Andhra University, India

\begin{abstract}
Global population is increasing day by day, which, in a way is leading to the utilization of natural resources and fuels. This phenomenon is gradually paving a way towards the depletion of these resources. One of such important necessity to human kind which is in the verge of depletion is the fossil fuel. Since it cannot be replenished, once it gets depleted, it cannot be produced again. Declining global oil producing capacity combined with a rising oil demand provides the most compelling global reason for alternative fuels. Present review focuses on the production of such fuels which are not only potential alternatives for fossil fuels, but also are eco-friendly in nature, which are called Biofuels. In this article, production of biofuel from plants \& algae; advantages \& disadvantages; and their role in effective replacement of existing fuels are mainly discussed.
\end{abstract}

Keywords: Fossil fuels; Global warming; Algal fuels; Jatropha; Green diesel; Gracilaria

Abbreviations: DMF: 2, 5 - Dimethyl furan; DME: Dimethyl Ether; SSCF: Simultaneous Saccharification \& Fermentation; SSF: Simultaneous Saccharification; CBP: Consolidated Bio Processing; PKV: Palm Kernel Cake; PM: Poultry Manure

\section{Introduction}

As today's technology progresses, the natural environment suffers from the detrimental effects of pollution [1]. Pollution of different environments is due to human activities in recent years [2]. Today's highly industrialized environment is charged with a multitude of potentially toxic chemicals [3]. Environmental pollution caused by the release of a wide range of compounds as a consequence of industrial progress has now assumed serious proportions [4]. The increase in industrial activities has intensified environmental pollution and the deterioration of some ecosystems, with the accumulation of pollutants [5]. This pollution and excessive exploitation of the natural resources such as fossil fuels, is gradually leading to the depletion of the reserves. Even though petroleum products are the major source of energy for industry as well as day today life, it also poses major concern over hydrocarbon release during its production. These are released into soil, air and water which posses a great danger to the natural habitats $[6,7]$. Sulphur emission through fossil fuel combustion is a major cause of acid rain and air pollution [8]. Apart from hydrocarbon release, the release of heavy metals into the environment [9] has become a major issue. As a remedy for all these problems, biological factors are coming into picture rather than using chemical substitutes which result in additional pollution. Methods like biosorption [10], biofuels production, bioremediation [11,12], phytoremediation [13] and biodegradation [14] are carried out in order to subside or decrease the effects of these pollutants in the environment [15]. Micro organisms play an important role in this process. Microorganisms are known for their ability to metabolize a variety of chemical compounds including aliphatic and aromatic hydrocarbon, fatty acids and other environmental pollutants [16].

World crude oil production is about 86 million barrels/day and estimated to reach 118 million barrels/day until 2030 [17]. With depletion of conventional petroleum reserves and increase of hydrocarbon fuel demand, there is no doubt that there will be a tremendous demand on the development of heavy oil reservoirs in the coming decades [18]. Rising oil prices and uncertainty over the security of existing fossil fuel reserves, combined with concerns over global climate change, have created the need for new transportation fuels and bio products to substitute for fossil carbon-based materials [19]. Microbial enhancing oil recovery (MEOR) processes [20], Thermal enhanced oil recovery [21] and gas injection [22] are also being employed for efficient recovery of oil. The search for a clean and cheaper fuel has become the need of hour [23]. Taking the waste product of one process and using it as input or fuel for another process is one way to accomplish this; it makes intelligent use of resources, decreases pollution, and broadens their application in sustainable approach [24]. With depletion of conventional petroleum reserves and increase of hydrocarbon fuel demand, there is no doubt that there will be a tremendous demand on the development of heavy oil reservoirs in the coming decades [25].

Oil is used worldwide as the main source for energy. It threatens the natural environment as its composition is made of complex molecules, when burned produces relatively high levels of carbon dioxide, sulphur dioxide and nitrogen oxides. Global warming, the increase of average world temperatures as a result of the greenhouse effect, is one of the impacts of oil using. Carbon dioxide contributes by about $50 \%$ to the greenhouse effect, in addition to methane, chlorofluorocarbons and nitrous oxide. Greenhouse effect could lead to a rise in average global temperatures between $1.5-4.5^{\circ} \mathrm{C}$ as early as the year 2030 [26].

Biotechnology has the potential to produce bulk compounds from renewable materials with reduced green house gases emission [27]. It has been suggested that large scale biofuel production, especially in combination with sequestration forestry, can achieve a low cost reduction in greenhouse gas levels, in particular $\mathrm{CO}_{2}$, and hence lead

*Corresponding author: Sameera.V, Biotechnology Department, REVA Institute of Science and Technology, Bangalore University, India, E-mail: sameera vadapalli@yahoo.com

Received March 01, 2011; Accepted April 20, 2011; Published April 28, 2011

Citation: Sameera V, Sameera C, Ravi Teja Y (2011) Current Strategies Involved in Biofuel Production from Plants and Algae. J Microbial Biochem Technol R1:002. doi:10.4172/1948-5948.R1-002

Copyright: (c) 2011 Sameera V, et al. This is an open-access article distributed under the terms of the Creative Commons Attribution License, which permits unrestricted use, distribution, and reproduction in any medium, provided the original author and source are credited 
to meeting the ultimate objective of the Kyoto Protocol to the UN framework convention on climate change (UNFCCC) [11]. Biofuel (the fuel derived from biological materials) substitutes fossil fuels and thus, through fossil fuels not extracted, prevents release of underground fossil carbon. Biofuel is also a renewable fuel that provides chemically stored energy that can potentially substitute fossil fuel with minimal infrastructural change and may provide a backstop technology until other innovative technologies take a sufficient market role [28]. Microbes are wonderful organisms which contribute more to the environment by playing vital role in various processes [29]. They are important organisms from industrial point of view of which bacteria are most important [30].

\section{Biofuel}

Nowadays there is an increasing interest in the development of more efficient and less time-consuming methods to assess the presence of microorganisms, as well as their viability for bioprocess control and improvement [31]. Biofuel is a type of fuel whose energy is derived from biological carbon fixation. Biofuels include fuels derived from biomass conversion, as well as solid biomass, liquid fuels and various biogases. Although fossil fuels have their origin in ancient carbon fixation, they are not considered biofuels by the generally accepted definition because they contain carbon that has been "out" of the carbon cycle for a very long time. Biofuels are gaining increased public and scientific attention, driven by factors such as oil price spikes, the need for increased energy security, concern over greenhouse gas emissions from fossil fuels, and government subsidies [32]. The increasing petroleum price and negative impact of fossil fuels on the environment are encouraging the use of lignocellulosic materials to help meet energy needs [33]. From the theoretical viewpoint, biofuels represent a direct substitute for fossil fuels used in transports because they are obtained from biomass, a renewable energy source. These can be integrated into already existing systems for fuel supply preparing thus the way to more performant fuels, such as hydrogen [34]. Even though the majority

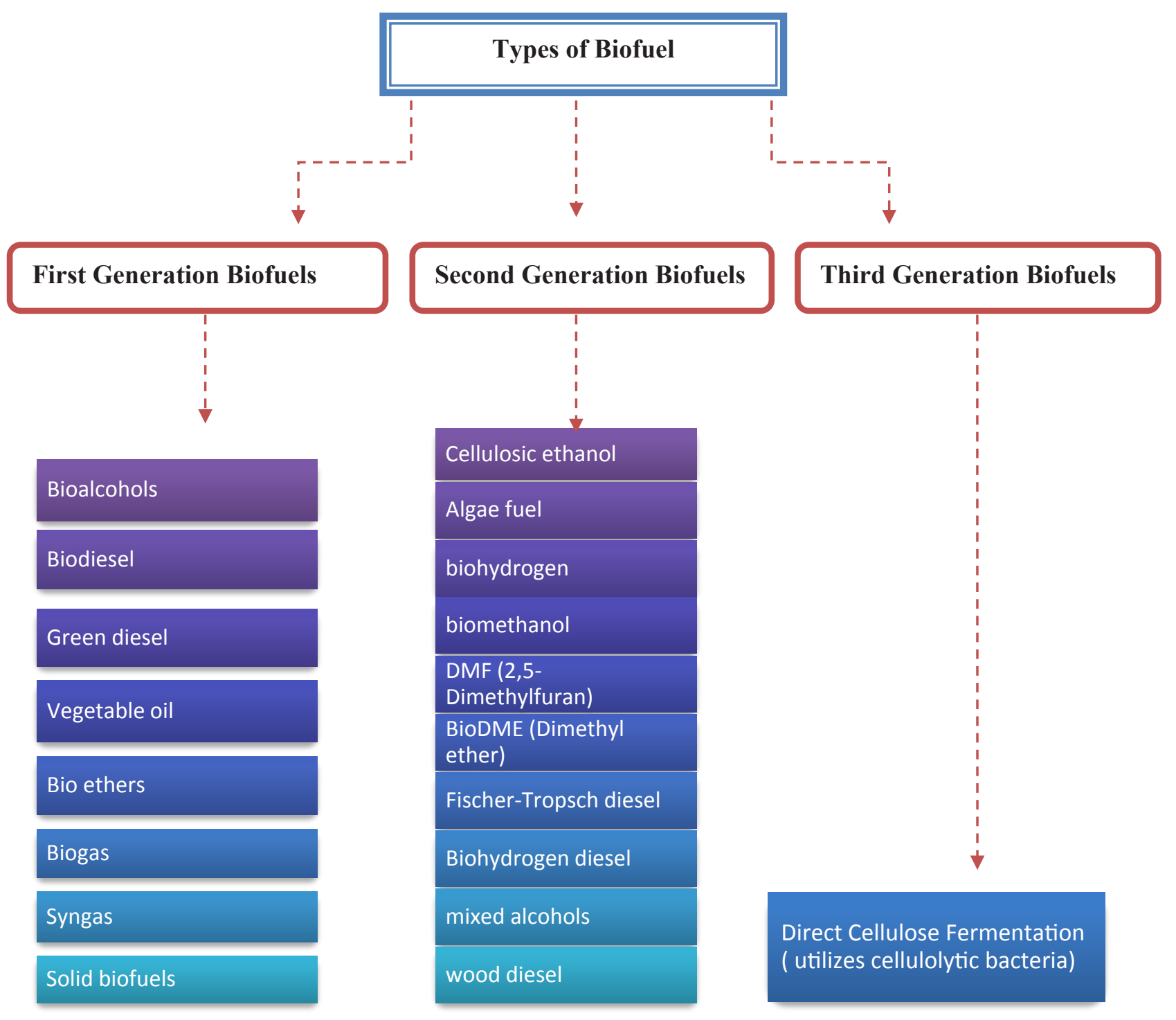

Figure 1: Classification of biofuels. 
of biofuels still are a lot more expensive than fossil fuels, their use is on increase worldwide due to financial incentives both for processing and consumption. Encouraged by various economic measures and instruments (especially subventions), the global production of biofuels is estimated currently at over 35 million tons [34].

The biotechnological route to 1,3-PD utilizes by-product glycerol from the biodiesel plant and presents a renewable, petroleum independent, eco-friendly route to an important raw material 1,3-PD while increasing the sustainability of the biodiesel plant by valorising its 'waste' glycerine into a valuable product [35].

The different kinds of biofuel which are produced are as follows

First generation biofuels: 'First-generation' or conventional biofuels are biofuels made from sugar, starch, and vegetable oil [32].

Bioalcohols: produced by the action of microorganisms and enzymes through the fermentation of sugars or starches (easiest) or cellulose.

Biodiesel: produced from oils or fats using Transesterification and is a liquid similar in composition to fossil/mineral diesel.

Green diesel: form of diesel fuel which is derived from renewable feedstock rather than the fossil feedstock used in most diesel fuels.

Vegetable oil: Straight unmodified edible vegetable oil is generally not used as fuel, but lower quality oil can and has been used for this purpose.

Bio ethers: Bio ethers (also referred to as fuel ethers or oxygenated fuels) are cost-effective compounds that act as octane rating enhancers.

Biogas: Biogas is methane produced by the process of anaerobic digestion of organic material by anaerobes.

Syngas: mixture of carbon monoxide, hydrogen and other hydrocarbons is produced by partial combustion of biomass, that is, combustion with an amount of oxygen that is not sufficient to convert the biomass completely to carbon dioxide and water

Solid biofuels: wood, sawdust, grass cuttings, domestic refuse, charcoal, agricultural waste, non-food energy crops and dried manure [32] (Figure 1).

Second Generation Biofuels: Second generation biofuels are biofuels produced from sustainable feedstock. Many second generation biofuels are under development such as Cellulosic ethanol, Algae fuel, biohydrogen, biomethanol, DMF, BioDME, Fischer-Tropsch diesel, biohydrogen diesel, mixed alcohols and wood diesel [32].

\section{Advantages}

The main advantage of biofuels is that, they are considered 'carbon neutral' by some people. This is because the carbon dioxide they release when burnt is equal to the amount that the plants absorbed out of the atmosphere. Therefore, they don't contribute to global warming. However, it does require some fuel to power the machinery on the farms where biofuels are produced. Still, they are better than fossil fuels! Research suggests that they reduce carbon emissions by $50-60 \%$ [36] (Figure 2).

\section{Disadvantages}

The main disadvantage of biofuels is that, setting aside land to grow biofuels means that there is less land to grow food. Some people

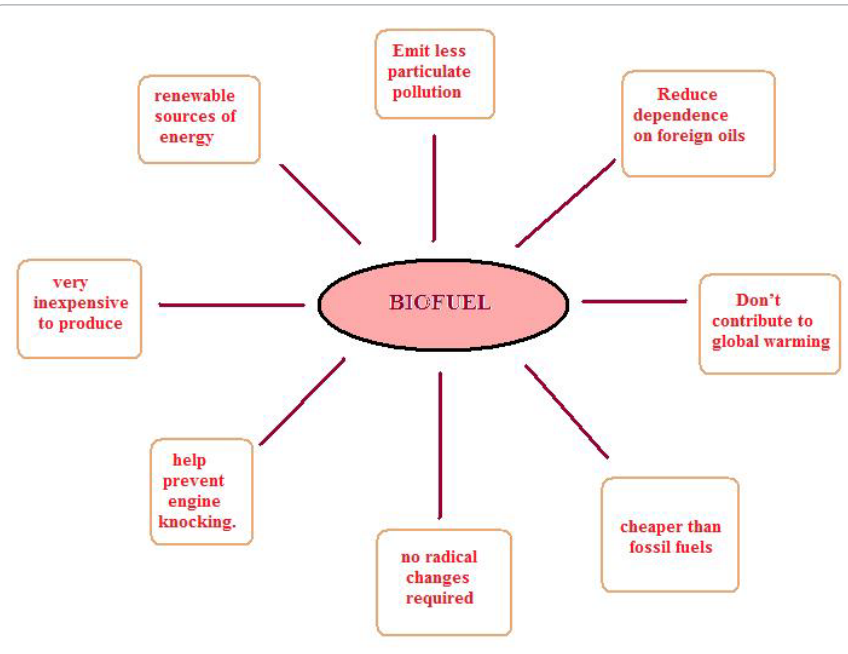

Figure 2: Advantages of biofuels.

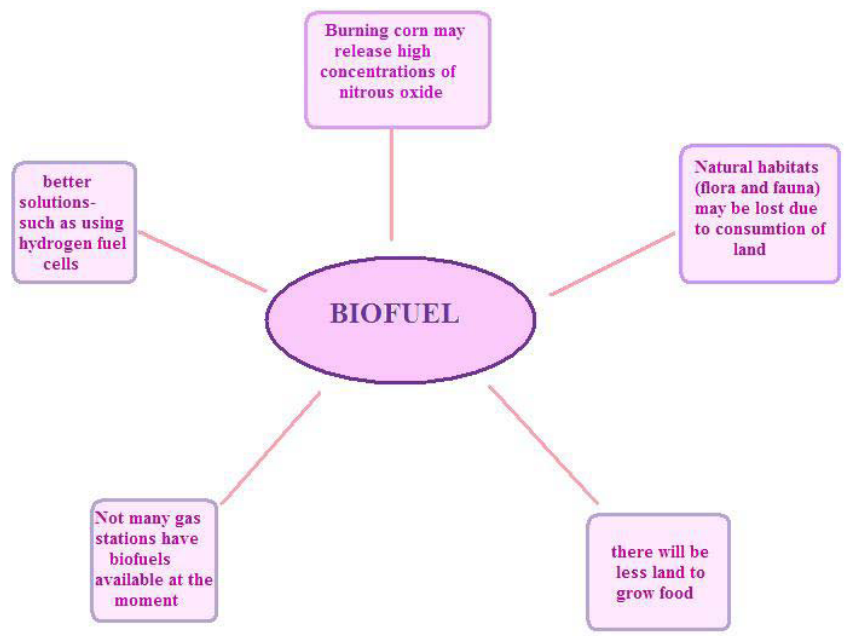

Figure 3: Disadvantages of biofuels

contend that this will lead to more people around the world starving as there will simply not be enough food to feed everyone. It is also possible that food prices will rise as a result. Agricultural crops most commonly used at present for biofuel production and climate protection can readily lead to enhanced greenhouse warming by $\mathrm{N}_{2} \mathrm{O}$ emissions [36] (Figure 3).

The main disadvantage of biofuels is that, setting aside land to grow biofuels means that there is less land to grow food. Some people contend that this will lead to more people around the world starving as there will simply not be enough food to feed everyone. It is also possible that food prices will rise as a result [36].

\section{Production of Biofuel from plants}

Biofuel can be produced by various techniques/methods utilizing a range of bio-resources like plants, algae, biomass, microbes, etc.

\section{Biodiesel}

The need to reduce greenhouse gas emissions and provide fuel security has increased the demand for oil-rich plants as raw materials 
for biodiesel production. Although vegetable oils have long been used for food, the ideal crop source for biodiesel products should consider other ecological, environmental and ethical concerns [37]. Biodiesel (methyl esters) is a clean alternative fuel which can be produced from many renewable resources. Palm oil like other vegetable oils can be used as feedstock for biodiesel production [38]. Ethanol produced by fermentation of plant biomass is considered to be an environmentally friendly alternative to fossil fuels. The search for renewable biomass sources that do not serve as human food and animal fodder have focused primarily on plant biomass that possesses mainly cellulose and lignocellulosic materials [34]. Although it is generally agreed that this type of biomass will ultimately be the primary source of ethanol biofuel in the future [36], there exist sources of simple hexoses that can fill a special niche in biofuel production but that have not been investigated for such an application.

Now-a-days, sweet sorghum juice is also been used as a substrate for the production of Bio Hydrogen [39].

Biofuel from plants can be produced by employing various processes as follows

Chemical process: A biodiesel production plant includes the following process. Various seeds, beans or algae are the source of the oils. These crops are delivered to the facility and stored on-site in silos or warehouses. The oil is extracted from the biomass source via chemical or mechanical processes. The fat or oil is combined with an alcohol such as methanol in the presence of a catalyst in a reactor. This reaction occurs at low temperatures (room temperature to about 140 degrees F) and low pressure and produces a crude biodiesel and glycerine. Once the reaction is complete, the glycerine, which is denser, is drawn off the bottom of the settling vessel. Next, the excess alcohol is removed from the biodiesel and from the glycerine and recovered by distillation [40] (Figure 4).

Pyrolysis Process: In a biodiesel production plant that utilizes pyrolysis, biomass feedstock is fed from a hopper typically as a crushed powder along with nitrogen into a thermal cracker where it is heated to 500 to $700^{\circ} \mathrm{C}$ in the absence of oxygen. The biomass is converted to pyrolysis vapour, gas, and char. This mixture is fed into a cyclone, which removes the char from the pyrolysis vapour. The vapour next enters a scrubber where it is sprayed with a liquid, which causes it to condense into pyrolysis oil. The oil is filtered, collected, and run through a series of reactors to upgrade the pyrolysis oil to a more desirable state for processing into transportation fuel [40] (Figure 5).

Gasification Process: In a biodiesel production plant that utilizes gasification, biomass feedstock is fed from a hopper typically as a crushed powder into a fluidized bed reactor. In the reactor, the feedstock mixes with sand as steam bubbles up through the sand at temperatures between 600 and $800^{\circ} \mathrm{C}$. The mixture of solids, vapour and gas then enters a thermal cracker that then forms Syngas, a combination of hydrogen and carbon monoxide along with tars and other solids. The solids are removed in cyclones, and a fluidized bed catalytic tar reformer converts the tars to additional Syngas. The Syngas then enters a scrubber where it is cooled and filtered. The dry gas later moves to a catalytic fuels synthesis unit, which in turn completes the Syngas conversion to mixed alcohols or other liquid transportation fuels [40] (Figure 6).

The production of biofuels from lignocellulosic biomass resources has the potential to increase biofuel production capacity whilst minimising the negative environmental and social impacts because lignocellulosic resources (for example: forestry residues, wheat straw, corn stover, etc.) do not compete directly with food production, or with land that may be needed for food production. Using these resources efficiently, however, requires conversion technologies such as advanced hydrolysis and fermentation to produce ethanol or the production of synfuels via gasification [41].

\section{Biofuel production using various plant sources}

Jatropha as the source for biofuels production: Jatropha oil is vegetable oil produced from the seeds of the Jatropha curcas, a plant that can grow in marginal lands. When Jatropha seeds are crushed, the resulting Jatropha oil can be processed to produce a high-quality biodiesel that can be used in a standard diesel car, while the residue (press cake) can also be processed and used as biomass feedstock to power electricity plants or used as fertilizer (it contains nitrogen, phosphorus and potassium).The plant may yield more than four times as much fuel per hectare as soybean and more than ten times that of maize (corn). A hectare of Jatropha has been claimed to produce 1,892 litres of fuel. Researchers at Daimler Chrysler Research explored the use of Jatropha oil for automotive use, concluding that although Jatropha oil as fuel "has not yet reached optimal quality, it already fulfils the EU norm for biodiesel quality". Archer Daniels Midland Company, Bayer Crop Science and Daimler AG have a joint project to develop Jatropha as a biofuel. Three Mercedes cars powered by Jatropha diesel have already put some 30,000 kilometres behind them. The project is supported by DaimlerChrysler and by the German Association for Investment and Development [42].

Mahua flower: Microorganisms are used as a tool by fermentation biotechnologists for the conversion of sugar into ethyl alcohol. Due to severe energy crisis in today's world, ethanol is considered to be the most suitable energy source amongst different fossil fuels. It has been producing by using a variety of substrates such as sugar cane juice, Sago starch, corn beet molasses, Jaggery etc. Mahua flowers are rich source of sugars, contains $72.9 \%$, proteins $4.4 \%$, Fat $0.5 \%$, calcium $150 \mathrm{mg}$, Iron $15 \mathrm{mg} / 100 \mathrm{gm}$, magnesium, copper and vitamins. In India, various parts of Andhra Pradesh Maharashtra, Chhattisgarh, some tribal communities are involved in cultivating and harvesting mahua flowers for alcoholic beverages using traditional methods. The extraction of sugars was carried by 1 kilogram of mahua flowers autoclaved with 2 litres of water at 1 steam pressure for 15 minutes [43].

Mahua flowers were used for the production of vinegar and alcohol production, and is likely to continue in places where they are available at low cost and where alcohol intended for used as potable spirits. Preparation of sugars and analysis of flowers from various districts have been studied, the analysis revealed that mahua contains $65-70 \%$ sugars, reducing sugars 48-55\%, Invert sugar 14-18,crude protein 4.0-6.5, Ferrous $21-48 \%$ fat $0.9-1.3$, ash $2.5-5.2 \%$, calcium $177-266 \%$. Biocatalyst Saccharomyces cerevisiae-3090 was obtained from the (NCIM), Pune. Ethanol tolerance yeast was isolated from fermenting cashew juice and even mahua flower is well abundant in India and it is having good keeping qualities. The utilization of mahua flower as a substrate for the production of ethanol though submerged fermentation has become a great economic advantage in the Indian context [43]

Watermelon as a source for ethanol production: Now-a-days, methods are being developed for the production of biofuels from watermelon. Two factors make watermelon worthy of consideration as a possible feedstock for ethanol biofuel production. First, about $20 \%$ of each annual watermelon crop is rejected for fresh fruit marketing 


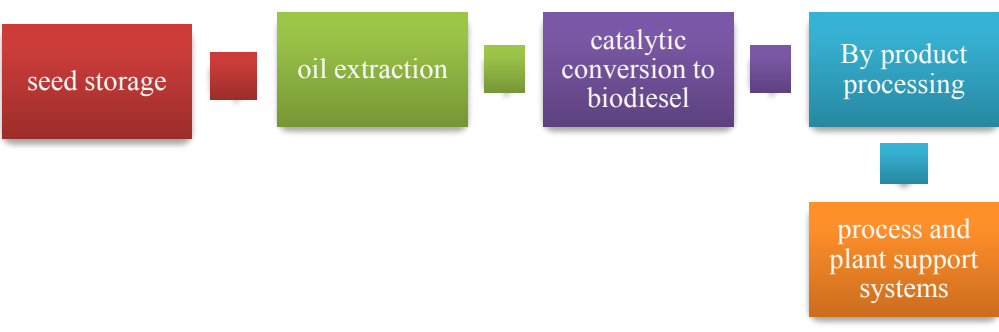

Figure 4: Flow chart for biodiesel production (chemical process).

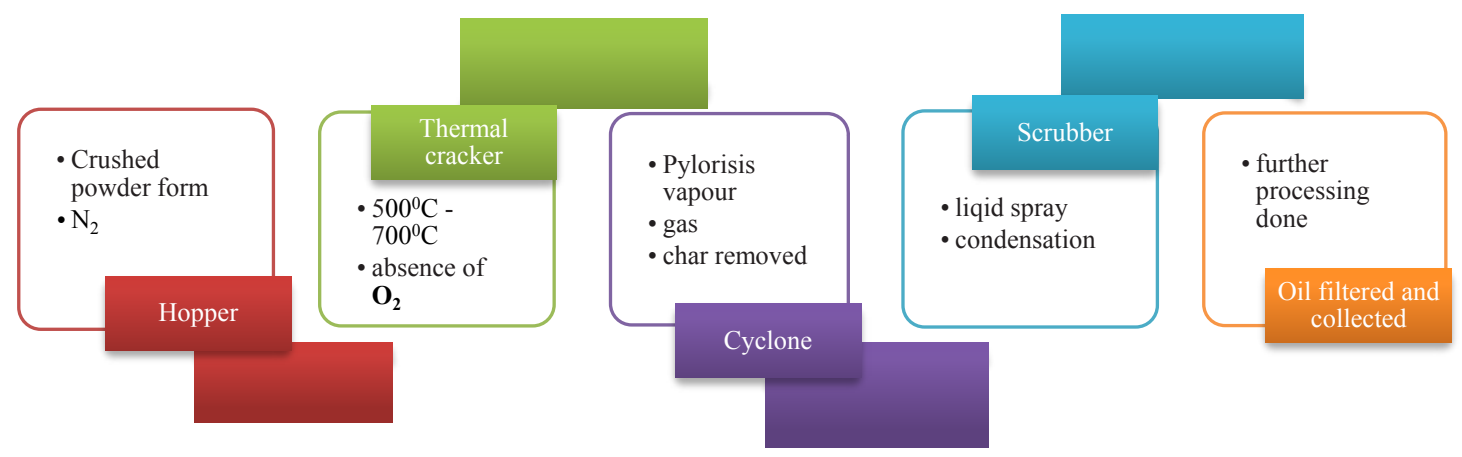

Figure 5: Process of Pyrolysis.

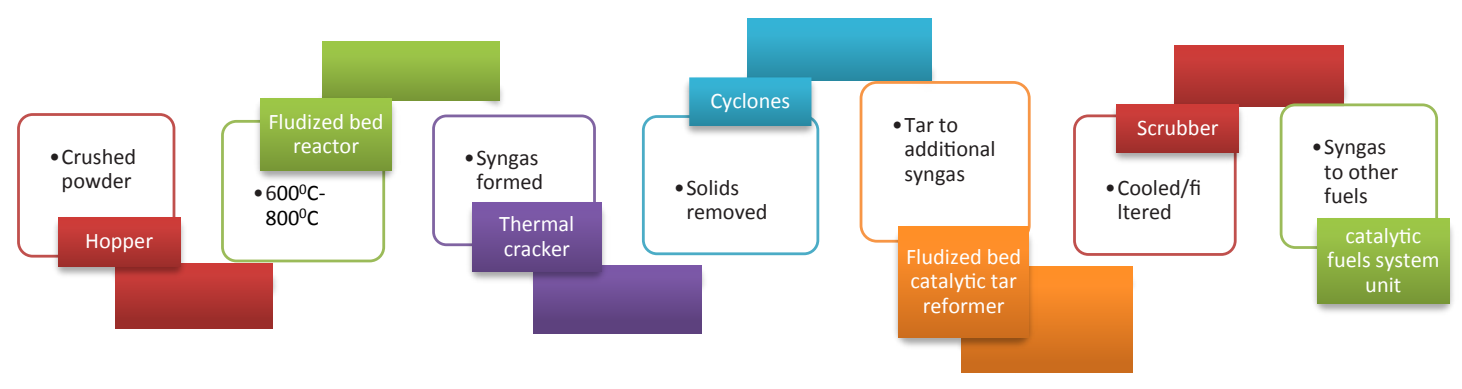

Figure 6: Gasification process.

because of surface blemishes or because fruits are misshapen; these 'culls', although internally sound, are left in the field. For the 2007 growing season, this would have amounted to around 360,000 t lost to US growers as a source of revenue [44]. Conversion on the premises of all or part of these cull watermelons to ethanol could, at the very least, provide supplemental on-farm fuel to the grower, or, in some cases, be sold on the ethanol biofuel market [44].

L-citrulline is a naturally occurring amino acid involved in the detoxification of catabolic ammonia and also serves as a precursor for L-arginine, the amino acid centrally involved in the production of the circulatory vasodilator, nitric oxide. Production of these two neutraceuticals from watermelon yields a waste stream that contains $\sim 10 \%$ (w/v) sugars that can be directly fermented to ethanol [44]. Fermentations were conducted in a BF-110 bench top modular fermentor system in this process.

Rape seed oil as a source for biofuels: Rape seed is one of the industrial plants whose economic significance is increasing in Poland and worldwide. Interest in rapeseed cultivation for fuel production is related with the possibility of rapeseed oil utilization in biofuel production [45]. The main factor affecting rapeseed usability as fodder, for food production and purposes are not related with food production [biofuel (RME), technical purposes, chemical, cosmetic and pharmaceutical industry] might be research targeted at improving varieties, seed yield, content of oil, proteins and active substances like tocopherols, as well as changes in composition and proportions of fatty acids and reduction of anti-nutritional compounds in seeds [45].

High content of oxygen dissolved in oil favours its reactions with double bonds of fatty acids and creation of hydroperoxides precursors of numerous processes generating substrates of free-radical oxidation transformations, and, as a result of molecule breakdown, alcohols, aldehydes and short-chain fatty acids. At the same time dehydration may lead to formation of ketones [46]. Used frying oil after it gets into sewage system is conductive to corrosion of metal and concrete elements. It also affects installations in waste water treatment plants. Fat covering elements of installations and therefore reducing flow in them decreases their efficiency, at the same time increases cost of their operation [46]. Proper management of used frying oils from gastronomy is an increasing ecological and economical problem, which 
can be solved through utilization of these wastes for purpose of fuel production.

Direct cellulose fermentation as biofuel source: Cellulose is the most abundant biopolymer in the world. Cellulose constitutes the highest proportion of municipal wastes; it represents a major source of renewable energy and raw materials. Therefore, the utilization of cellulosic wastes to produce energy is potentially of great importance [47]. Discarded cellulosic biomass derived from forestry, agriculture and municipal sources are potential feedstocks for the synthesis of biofuels (and other value-added bioproducts) that could displace fossil fuel consumption and reduce greenhouse gas emissions [48]. The crystalline structure of cellulose however makes it difficult to hydrolyze. Conventional production of ethanol or $\mathrm{H}_{2}$ from cellulose via fermentation involves a complex process of pre-treatment including:

(i) Cellulase production,

(ii) Hydrolysis of cellulose and hemicelluloses (if present), followed by

(iii) Fermentation of hexose sugars generated by cellulose hydrolysis and pentose sugars generated by hemicelluloses hydrolysis (if present). Current strategies to produce fuel ethanol from cellulose, referred to as "second-generation" biofuels, utilize simultaneous saacharification and fermentation (SSF) or simultaneous saacharification and co-fermentation (SSCF) [48].

Consolidated bioprocessing (CBP) is an alternative processing strategy in which cellulase production, substrate hydrolysis and fermentation are accomplished in a single process step by microorganisms that express cellulolytic (and hemicellulolytic) enzymes. CBP offers the potential for lower biofuel production costs due to simpler feedstock processing, lower energy inputs (and therefore better energy balance) and higher conversion efficiencies than SSF based processes. CBP is an economically attractive near-term goal for process for "third generation" biofuel production [48].

Apart from these, other substrates which can be used for biofuels production are as follows [49].

» Algae

»Camelina

» Calophyllum inophyllum L.,

» Castor bean (Ricinus communis)

»Citrullus colocynthis (Tumba)

$»$ Flax

» Jojoba (Simmondsia chinesis)

» Jerusalem artichoke (Helianthus tuberosus L.)

» Kenaf Karanja (Pongamia pinnata)

» Kokum (Garcinia indica)

» Moringa oleifera Mahua (Madhuca indica)

$» \quad$ Neem (Azadirachta indica)

» Simarouba (Simarouba glauca) [49].

Production of biofuels from algae: Algae are the fastest-growing plants and the most widely distributed organisms in Nature. Microalgae are veritable miniature biochemical factories and appear more photosynthetically efficient than terrestrial plants and are efficient $\mathrm{CO}_{2}$ fixers. The ability of algae to fix $\mathrm{CO}_{2}$ has been proposed as a method of removing $\mathrm{CO}_{2}$ from flue gases from power plants, and thus can be used to reduce emission of green house gases [50]. The dry cell weight contains about $50 \%$ oil. Algae are a large group of photoautotrophic, mixotrophic and heterotrophic lower plants. Algae can be typically subdivided into two major categories, based on their relative sizes: macroalgae and microalgae. Microalgae are capable of producing 30 times the amount of oil per unit area of land, compared to oilseed crops. It is the first largest biomass resource. Microalgae are abundant in diverse ecological aquatic habitats such as fresh, brackish, marine, and hypersaline water environments within a wide range of temperatures, $\mathrm{pH}$ values and salinity. Production of bioethanol from algal biomass is being harnessed extensively due to its suitable utilization on a commercial scale [51].Theoretically; microalgae could grow in different kind of water, nutrients and land saving sites for oil production. Even better production can be achieved in the desert, where the sunlight is stronger [52]. As the focus on algae as the fuel of the future increases, the need to make algae biofuel more sustainable falls into a handful of categories from economic assessment to engineering [53].

There are a large number of potential pathways for the conversion of microalgal biomass into lipids, ethanol, hydrogen, methane, hydrocarbon and carbohydrates. The lipids can be refined into biodiesel for land transportation and even for aviation use. Microalgal biodiesel has become one of the potential third-generation biofuels. $\mathrm{CO}_{2}$, sunlight, water and land are the main natural resources required for algal production [52].

The crude glycerol poultry litter and algae-switch grass mixtures can also be used as substrates under sterile and non-sterile conditions as substrate for biofuel production. With sterile crude glycerol-poultry litter substrate, methanogenic consortia immobilized on peanut hull recorded the highest cumulative biogas and methane production [54]. In addition commercially cultivated microalgae, including both Algae and Cyanobacteria are marketed as nutritional supplements, such as Spirulina, Chlorella and the Vitamin-C supplement, Dunaliella which is high in beta-carotene. The oils from some Algae have high levels of unsaturated fatty acids. For example, Parietochloris incisa is very high in arachidonic acid, where it reaches up to $47 \%$ of the triglyceride pool [55].

Now-a-days, different tools have come into picture in order to make the identification of micro organisms easier like BLAST [56], which can be utilized for improved production of biofuels.

\section{Advantages of algae}

- Algae can be grown using land and water unsuitable for plant or food production, unlike some other first- and secondgeneration biofuel feedstocks.

- Select species of algae produce bio-oils through the natural process of photosynthesis - requiring only sunlight, water and carbon dioxide.

- Growing algae consume carbon dioxide; this provides greenhouse gas mitigation benefits.

- Bio-oil produced by photosynthetic algae and the resultant biofuel will have molecular structures that are similar to the petroleum and refined products we use today. 
- Algae have the potential to yield greater volumes of biofuel per acre of production than other biofuel sources. Algae could yield more than 2000 gallons of fuel per acre per year of production. Approximate yields for other fuel sources are far lower: - Palm - 650 gallons per acre per year - Sugar cane - 450 gallons per acre per year - Corn - 250 gallons per acre per year - Soy -50 gallons per acre per year

- Algae used to produce biofuels are highly productive. As a result, large quantities of algae can be grown quickly, and the process of testing different strains of algae for their fuel-making potential can proceed more rapidly than for other crops with longer life cycles.

- If successful, bio-oils from photosynthetic algae could be used to manufacture a full range of fuels including gasoline, diesel fuel and jet fuel that meet the same specifications as today's products [57].

\section{Disadvantages to algae oil production}

- Produces unstable biodiesel with many polyunsturates.

- Relatively new technology.

- Biodiesel performs poorly compared to its mainstream alternative [58].

Research into algae for the mass-production of oil is mainly focused on microalgae; organisms capable of photosynthesis that are less than $0.4 \mathrm{~mm}$ in diameter, including the diatoms and cyanobacteria; as opposed to macroalgae, such as seaweed. The preference towards microalgae is due largely to its less complex structure, fast growth rate, and high oil content (for some species). However, some research is being done into using seaweeds for biofuels, probably due to the high availability of this resource.

The following species listed are currently being studied for their suitability as a mass-oil producing crop, across various locations worldwide:

- Botryococcus braunii

- Chlorella

- Dunaliella tertiolecta

- Gracilaria

- Pleurochrysis carterae (also called CCMP647).
- Sargassum, with 10 times the output volume of Gracilaria [59] (Figure 7).

Botryococcus braunii: Botryococcus braunii (Bb) is a green, pyramid shaped planktonic microalga that is potentially important in the field of biotechnology. Colonies held together by a lipid biofilm matrix can be found in temperate or tropical oligotrophic lakes and estuaries, and will bloom when in the presence of elevated levels of dissolved inorganic phosphorus. The species is notable for its ability to produce high amounts of hydrocarbons, especially oils in the form of Triterpenes that are typically around 30-40 percent of their dry weight. Compared to other green algae species, it has a relatively thick cell wall that is accumulated from previous cellular divisions; making extraction of cytoplasmic components rather difficult. Fortunately, much of the useful hydrocarbon oil is outside of the cell.

The practice of farming and cultivating algae is known as algaculture. Botryococcus braunii has great potential for algaculture because of the hydrocarbons it produces, which can be chemically converted into fuels. Up to $86 \%$ of the dry weight of Botryococcus braunii can be long chain hydrocarbons. The vast majority of these hydrocarbons are Botryococcus oils: botryococcenes, alkadienes and alkatrienes. Transesterification can not be used to make biodiesel from Botryococcus oils. This is because these oils are not vegetable oils in the common meaning, in which they are fatty acid triglycerides. While Botryococcus oils are oils of vegetable origin, they are inedible and chemically very different, being triterpenes, and lack the free oxygen atom needed for Transesterification. Botryococcus oils can be used as feedstock for hydrocracking in an oil refinery to produce octane (gasoline, a.k.a. petrol), kerosene, and diesel. Botryococcenes are preferred over alkadienes and alkatrienes for hydrocracking as botryococcenes will likely be transformed into a fuel with a higher octane rating [60].

Chlorella: Chlorella is a genus of single-celled green algae, belonging to the phylum Chlorophyta. It is spherical in shape, about 2 to $10 \mu \mathrm{m}$ in diameter, and is without flagella. Chlorella contains the green photosynthetic pigments chlorophyll-a and -b in its chloroplast. Through photosynthesis, it multiplies rapidly requiring only carbon dioxide, water, sunlight and a small amount of minerals to reproduce [61]. Chlorella can be efficiently used for the production of biofuels.

Chlorella biofuel is a very clean type of non-fossil fuel and, when one day it becomes available on a mass scale, it could make a significant contribution to reduce carbon emissions. The beauty of it is that there is a limitless amount of algae growing in oceans, lakes,

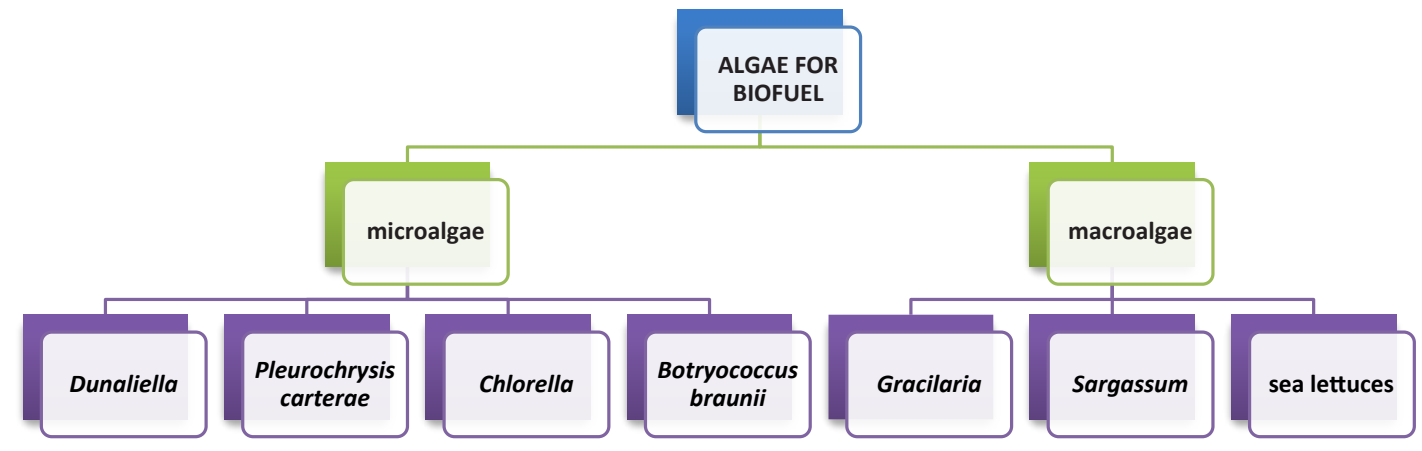

Figure 7: Classification of algae used in biofuels production. 
and rivers, throughout the world [62]. Recently there have been some promising technological breakthroughs in this field. Not too long ago the American Chemical Society released a statement saying that chemists reported the development of what they termed the first economical, eco-friendly process to produce chlorella biofuel, with the added bonus of not producing any wastewater [62]. Research is going on presently on the use of Poultry manure (PM in mixotrophic cultivation of microalga, Chlorella vulgaris in order to improve the biofuels production [63]

One of the most exciting aspects of chlorella biofuel is that as a potential source of food and energy, chlorella's photosynthetic efficiency can reach levels as high as sugar cane, or $8 \%$. Through photosynthesis it multiplies rapidly requiring only carbon dioxide, water, sunlight, and a small amount of minerals to reproduce. Besides the efficiency advantage, there are other factors that make chlorella biofuel a very attractive option: algae can be grown in non-arable land; it can be grown on marine or waste water, therefore saving fresh water; it avoids the food versus fuel problem. The drawback is that harvesting still is expensive; therefore before chlorella biofuel becomes economically viable for mass consumption, more research will be necessary. But it's definitely a very promising renewable energy alternative.

Dunaliella tertiolecta: Dunaliella is a genus of algae, specifically of the Dunaliellaceae. Dunaliella sp. are motile, unicellular, rod to ovoid shaped $(9-11 \mu \mathrm{m})$ green algae (Chlorophyceae), which are common in marine waters. D. tertiolecta is a flagellated unicellular marine microalga belonging to the Chlorophyta phylum. The organisms are relatively simple to cultivate and do not clump or form chains [64]

A study was performed to discover genes that encode enzymes involved in the biosynthesis of biofuel precursors in the microalgae Dunaliella tertiolecta and to describe the relevant metabolic pathways. D.tertiolecta has the ability to produce large quantities of lipids and starch (up to $67 \%$ and $27 \%$ of organism dry weight, respectively), rapid growth rate in hyper saline environments which aids in maintenance of pure cultures. Lack of a rigid cell wall eases product extraction and genetic manipulation. These unique physiological and structural traits gives $D$. tertiolecta considerable advantages over model organisms such Chlamydomonas reinhardtii as feedstock for biofuel production [65].

Gracilaria \& Sargassum: Gracilaria and Sargassum, are rich in polysaccharide that can be transformed to ethanol (alcohol) to produce gasohol.

Gracilaria is a genus of red algae (Rhodophyta) notable for its economic importance as an agarophyte, as well as its use as a food for humans and various species of shellfish. Various species within the genus are cultivated in various parts of the developing world, including Asia, South America, Africa and Oceania [66].

Sargassum is a genus of brown (class Phaeophyceae) macroalga (seaweed) in the order Fucales. Numerous species are distributed throughout the temperate and tropical oceans of the world, where they generally inhabit shallow water and coral reefs. However, the genus may be best known for its planktonic (free-floating) species. Any number of the normally benthic species may take on a planktonic, often pelagic existence after being removed from reefs during rough weather [67].

Researchers worldwide have long intended to apply lipid-laced algae to biofuel production but have been hampered by high extraction costs and low conversion rates [68].

According to the COA, Gracilaria a genus of red algae has been widely farmed along the coast of Taiwan for decades, as it is a food source for humans as well as various species of farmed shellfish. The farming area of gracilaria was 253 hectares in 2006 [68].

However, the officials said that demand for gracilaria dropped several years ago and COA researchers at the Fisheries Research Institute started studies to discover possible alternative uses. According to a previous study, Sargassum has 10 times the output volume of Gracilaria [68].

Pleurochrysis carterae: Pleurochrysis carterae is a unicellular coccolithophorid alga that has the ability to calcify subcellularly. They produce calcified scales, known as coccoliths, which are deposited on the surface of the cell resulting in the formation of a coccosphere. Pleurochrysis carterae produce heterococcoliths which are composed of crystal units of variable shapes and sizes [69].

\section{Other methods}

Scientists have employed many other methods by which biofuels can be produced. For example,

- Biodiesel production was achieved by blending of poultry manure (PM), paper pulp and algae waste sludge in co-digestion producing biomethane, digestate, which is again filtrated to get semi-solid and aqueous, the former as biofertilizer and latter was used in algal cultivation to enhance algal biomass for biodiesel production [70].

- Dimethyl/diethyl carbonate can be adopted as an extraction solvent and Trans-esterification reagent at the same time for in situ lipase-catalyzed reactive extraction of oilseeds for biodiesel production [71]

- Palm oil like other vegetable oils can be used to create biodiesel, as either a simply processed palm oil mixed with petrodiesel, or processed through Transesterification to create a palm oil methyl ester blend, which meets the International EN 14214 specification. From 2007, all diesel sold in Malaysia must contain 5\% palm oil. Malaysia is emerging as one of the leading biofuel producers, with 91 palm oil plants approved and a handful now in operation [72]. The global production of Palm Kernel Cake (PKC), a by-product of oil extraction from the nut of the palm tree, Elaeis guineensis, is ever increasing due to the tremendous growth of the oil palm industry in many parts of Asia and Africa (PORLA, 2000) [73].

- Niger seed oil cake (Guizotia abyssinica) is cultivated in tropical countries and is quite expensive as it is imported usually from Ethiopia and India. Niger seed oil has been identified as a potential biodiesel crop because of the presence of $50-60 \%$ the oil called biocrude, which can be converted into biodiesel by chemical or lipase mediated esterification [74].

- Corn steep liquor (by-product of the corn milling industry) is a low-cost nutritional medium used successfully in the production of ethanol by Zymomonas mobilis, succinic acid by Anaerobiospirillum succiniciproducens and arabinanase by Fusarium oxysporum [75].

- The heteropolymer xylan [31] represents the most abundant hemicellulosic polysaccharide and is composed primarily of xylose, arabinose, and glucuronic acid. Microbes have evolved a plethora of enzymatic strategies for hydrolyzing xylan into its constituent sugars for subsequent fermentation to biofuels [76]. 
- The substrate being night soil which is extensively rich in nitrogen content and thus can be added to the cattle dung digesters to combat the nitrogen deficiency and also improve the biogas production [77].

- Ethanol can be produced using corn, switchgrass, and wood biodiesel also can be produced using soybeans [78] and sunflower [79].

- Saccharomyces cerevisiae (bakers' yeast) is used as host for the production of industrial bioethanol from plant biomass [80].

\section{Conclusion}

Biofuels can be produced by various means which include lignocellulosic wastes, plants, algae, starch, vegetable oils, etc. Algae are considered as Third generation biofuels due to their novel properties and important advantages like, they can be grown on the land and water which may be unsuitable for the growth of plants; they produce biofuel by utilizing natural resources such as sunlight, water, and $\mathrm{CO}_{2}$, etc. They are even comfortable to grow and maintain. Thus, taking into account of the above mentioned points, a conclusion can be drawn that algal fuel would be the superior alternative for the fossil fuels.

\section{References}

1. Gurel L, senturk I, Bahadir T, Buyukgungor H (2010) Treatment of Nickel Plating Industrial Wastewater by Fungus Immobilized onto Rice Bran. J Microbial Biochem Technol 2: 34-37.

2. Gowrang More, Roshan Kumar, Muralidhar Talked (2011) Attenuation of the heavy metals present in the mill tailings of kolar gold fields (kgf). J Bioremed Biodegrad 331

3. Fayidh MA, Babuskin S, Sabina K, Sukumar M, Sivarajan M (2011) Integrated Approach to the Problems of Dye Wastewater by Sonolysis and Biological Treatment. J Microbial Biochem Technol 3: 60-66.

4. Gursahani YH, Gupta SG (2011) Decolourization of textile effluent by a thermophilic bacteria Anoxybacillus rupiensis. J Pet Environ Biotechnol 2: 111

5. Kumar KK, Prasad MK, Sarma GVS, Murthy CVR (2009) Removal of Cd (II) from Aqueous Solution Using Immobilized Rhizomucor Tauricus. J Microbial Biochem Technol 1: 15-21.

6. Karthikeyan M, Radha KV (2011) Remediation of oil spills using biosurfactant obtained from Pseudomonas putida. J Bioremed Biodegrad

7. Rodrigues DF (2011) Biofilters: A Solution for Heavy Metals Removal from Water? J Bioremed Biodegrad 2: e101.

8. Amin GA (2011) Integrated Two-Stage Process for Biodesulfurization of Model Oil by Vertical Rotating Immobilized Cell Reactor with the Bacterium Rhodococcus erythropolis. J Pet Environ Biotechnol 2: 107-111.

9. Kumar NK, Reddy DSR, Venkateswarlu P (2010) Application of Response Surface Methodology for Optimization of Chromium Biosorption from an Aqueous Solution onto Syzigium cumini (java) Seed Powder. J Microbial Biochem Technol 2: 20-27.

10. Kurnaz SU, Buyukgungor H (2009) Assessment of Various Biomasses in the Removal of Phenol from Aqueous Solutions. J Microbial Biochem Technol 1: 47-50.

11. Jame SA, Rashidul Alam AKM, Fakhruddin ANM, Alam MK (2010) Degradation of Phenol by Mixed Culture of Locally Isolated Pseudomonas Species. J Bioremed Biodegrad 1: 102-106.

12. Olusola SA, Anslem EE (2010) Bioremediation of a Crude Oil Polluted Soil with Pleurotus Pulmonarius and Glomus Mosseae Using Amaranthus Hybridus as a Test Plant. J Bioremed Biodegrad 1: 113-119.

13. Sonoki T, Kajita S, Uesugi M, Katayama Y, limura Y (2011) Effective Remova of Bisphenol a from Contaminated Areas by Recombinant Plant Producing Lignin Peroxidase. J Pet Environ Biotechnol 2: 105-108.

14. Mirdamadian SH, Emtiazi G, Golabi MH, Ghanavati H (2010) Biodegradation of Petroleum and Aromatic Hydrocarbons by Bacteria Isolated from PetroleumContaminated Soil. J Pet Environ Biotechnol 1: 102-107.
15. Bordenave S, Goni-Urriza M, Caumette P, Duran R (2009) Differential Display Analysis of cDNA Involved in Microbial Mats Response after Heavy Fuel Oil Contamination. J Microbial Biochem Technol 1: 1-4.

16. Poornima K, Karthik L, Swadhini SP, Mythili S, Sathiavelu A(2010) Degradation of Chromium by Using a Novel Strains of Pseudomonas Species. J Microbia Biochem Technol 2: 95-99.

17. Aghamiri SF, Kabiri K, Emtiazi G (2011) A Novel Approach for Optimization of Crude Oil Bioremediation in Soil by the Taguchi Method. J Pet Environ Biotechnol 2: 110-116.

18. Ghoodjani E, Kharrat R, Vossoughi M, Bolouri SH (2011) A Review on Therma Enhanced Heavy Oil Recovery from Fractured Carbonate Reservoirs. J Pet Environ Biotechnol 2: 109-116.

19. Zhang B, Shahbazi A (2011) Recent Developments in Pretreatmen Technologies for Production of Lignocellulosic Biofuels. J Pet Environ Biotechnol 2: 108-116.

20. Amin GA (2010) A Potent Biosurfactant Producing Bacterial Strain for Application in Enhanced Oil Recovery Applications. J Pet Environ Biotechnol 1 104-109.

21. Ghoodjani E, Kharrat R, Vossoughi M, Bolouri SH (2011) A Review on Therma Enhanced Heavy Oil Recovery from Fractured Carbonate Reservoirs. J Pet Environ Biotechnol 2: 109-116.

22. Ghoodjani E, Bolouri SH (2011) Experimental Study of $\mathrm{CO}_{2}-\mathrm{EOR}$ and $\mathrm{N}_{2}$-EOR with Focus on Relative Permeability Effect. J Pet Environ Biotechnol 2: 106 111

23. Sangeetha R, Sivaprakash B, Karunanithi T (2011) Response surface optimization of hydrogen production by Clostridium pasteurianum and design of a chemostat using MATLAB. J Microbial Biochem Technol 243.

24. Iyovo GD, Du G, Chen J (2010) Sustainable Bioenergy Bioprocessing: Biomethane Production, Digestate as Biofertilizer and as Supplemental Feed in Algae Cultivation to Promote Algae Biofuel Commercialization. J Microbia Biochem Technol 2: 100-106

25. Ghoodjani E, Kharrat R, Vossoughi M, Bolouri SH (2011) A Review on Therma Enhanced Heavy Oil Recovery from Fractured Carbonate Reservoirs. J Pet Environ Biotechnol 2: 109-116.

26. Ali Elredaisy SM (2010) Ecological Benefits of Bioremediation of Oi Contaminated Water in Rich Savannah of Palogue, Upper Nile Area-Southern Sudan. J Bioremed Biodegrad 1: 103-110.

27. Vanajakshi J, Annapurna J, Priyanka A (2011) Enhanced production of 1 3-Propanediol by a newly isolated Klebsiella pneumoniae 141B strain using crude glycerol as a substrate. J Microbial Biochem Technol 252.

28. Korobeinikov A, Read P, Parshotam A, Lermit J (2005) Modelling Key Marke Impacts And Land Allocation For Biofuel Production And Forestry. Journal of Applied Mathematics and Decision Sciences 2006: 1-12

29. Prathusha K, Suneetha V (2011) Production, mechanistic characterization and properties of Pectinases from Bacillus sps. isolated from fruit industrial waste. $\mathrm{J}$ Bioremed Biodegrad

30. Shukla P, Patel N, Mohan Rao R, Shukla J, Verma S, et al. (2011) Isolation and characterization of polyhydroxyalkanoate and exopolysaccharide producing Bacillus sp. PS1 isolated from sugarcane field in Bhilai, India. J Microbial Biochem Technol 3: 33-35

31. Lopes F, Motta F, Andrade CCP, Rodrigues MI, Maugeri-Filho F (2011) Thermo-Stable Xylanases from Non Conventional Yeasts. J Microbial Biochem Technol 3: 36-42.

32. http://en.wikipedia.org/wiki/Biofue

33. Nicoletta Nassi o Di Nasso, Neri Roncucci, Federico Triana, Cristiano Tozzini, Enrico Bonari (2011) Seasonal nutrient dynamics and biomass quality of gian reed (Arundo donax L.) and miscanthus (Miscanthus $x$ giganteus Greef et Deuter) as energy crops. Italian Journal of Agronomy 6: 24

34. Victor P, Simona F, Andreea C, Sorina J (2010) Current Perspectives and Challenges of Biofuel Production and Consumption. Romanian Journal of Economics 31: 107-128

35. Guneet K, Ashok KS, Subhash C (2011) Statistical Optimization of 1 3-Propanediol Production by Clostridium Diolis. J Microbial Biochem Technol 16. 
Citation: Sameera V, Sameera C, Ravi Teja Y (2011) Current Strategies Involved in Biofuel Production from Plants and Algae. J Microbial Biochem Technol R1:002. doi:10.4172/1948-5948.R1-002

Page 10 of 8

36. http://wanttoknowit.com/advantages-of-biofuels/

37. Gustavo GL Costa, Kiara CC, Luiz EV Del Bem, Aline CL, Muciana AS Cunha (2010) Transcriptome analysis of the oil-rich seed of the bioenergy crop Jatropha curcas L. BMC Genomics 11: 462

38. Meng L, Salihon J (2011) Conversion of Palm Oil to Methyl and Ethyl Ester using Crude Enzymes. J Biotechnol Biomaterial 1: 110-114

39. Nagaraj D, Umakanth AV, Prakasham RS (2011) Impact of microbial adaptation on biohydrogen production using sweet Sorghum juice. World Congress on Biotechnology 610

40. http://teeic.anl.gov/er/biomass/restech/desc/biodieselplants/index.cfm

41. Raphael S, Ausilio B, Nilay S (2009) The greenhouse gas emissions performance of cellulosic ethanol supply-chains in Europe. Biotechnol Biofuels 2: 15

42. http://en.wikipedia.org/wiki/Jatropha_oil

43. Benerji DSN, Ayyanna C, Rajini K, Rao BS, Banerjee DRN, et al. (2010) Studies on Physico-Chemical and Nutritional Parameters for the Production of Ethanol from Mahua Flower (Madhuca indica) Using Saccharomyces Cerevisiae 3090 Through Submerged Fermentation (smf). J Microbial Biochem Technol 2 46-50.

44. Wayne WF, Benny DB, Vincent MR (2009) Watermelon juice: a promising feedstock supplement, diluent, and nitrogen supplement for ethanol biofue production. Biotechnol Biofuels 2: 18

45. Kachel MJ, Szpryngiel M (2008) Influence on drying condition on quality properties of rapeseed. Int. Agrophysics 22: 327-331

46. Szmigielski M, Maniak B, Piekarski W (2008) Evaluation of chosen quality parameters of used frying rape oil as fuel biocomponent. Int Agrophysics 22 361-364

47. El-Bondkly AM, Aboshosha AAM, Radwan NH, Dora SA (2010) Successive Construction of $B$-Glucosidase Hyperproducers of Trichoderma Harzianum Using Microbial Biotechnology Techniques. J Microbial Biochem Technol 2 70-73.

48. Carlo RC, Richard S, Nazim C, David BL (2008) Third Generation Biofuels via Direct Cellulose Fermentation. Int J Mol Sci 9: 1342-1360

49. http://www.jatrophabiodiesel.org/index.php

50. Vishwanath P, Khanh-Quang T, Hans RG (2008) Towards Sustainable Production of Biofuels from Microalgae. Int J Mol Sci 9: 1188-1195

51. Sushama SG (2011) Enzymatic saccharification of the Kelp polysaccharides for the bioethanol production J Microbial Biochem Technol 109.

52. Shuhao H, Renjie D, Zhongming W, Changle P, Zhenhong Y (2011) Available Resources for Algal Biofuel Development in China. Energies 4: 1321-1335

53. Iyovo GD, Du G, Chen J (2010) Poultry Manure Digestate Enhancement of Chlorella Vulgaris Biomass Under Mixotrophic Condition for Biofuel Production. $\mathrm{J}$ Microbial Biochem Technol 2: 51-57

54. Arguijo Portillo NV, Chinnasamy S, Das KC, Balagurusamy N (2011) Performance of two methanogenic consortia immobilized on natural supports in methane production during co-digestion process . J Microbial Biochem Technol 27.

55. Soumen R, Ashutosh K, Prem P, Hindumathy CK (2011) Algal ilnnovation - An alternative source for existing crisis. J Microbial Biochem Technol 267.

56. Croce O, Chevenet F, Christen R (2010) A New Web Server for the Rapid Identification of Microorganisms. J Microbial Biochem Technol 2: 84-88.

57. http://www.exxonmobil.com/Corporate/energy_vehicle_algae.aspx

58. http://www.environblog.com/2008/06/algae-oil-production-disadvatagesbenefits.html

59. http://en.wikipedia.org/wiki/Algae_fuel

60. http://en.wikipedia.org/wiki/Botryococcus_brauni

61. http://en.wikipedia.org/wiki/Chlorella

62. http://www.energyrefuge.com/archives/chlorella-biofuel.htm

63. Iyovo GD, Du G, Chen J (2010) Poultry Manure Digestate Enhancement of Chlorella Vulgaris Biomass Under Mixotrophic Condition for Biofue Production. J Microbial Biochem Technol 2: 51-57.

64. http://en.wikipedia.org/wiki/Dunaliella

65. Hamid RY, Berat ZH, Kyle B, Jordan P (2011) Transcriptome sequencing and annotation of the microalgae Dunaliella tertiolecta: Pathway description and gene discovery for production of next-generation biofuels BMC Genomics 12 148

66. http://en.wikipedia.org/wiki/Gracilaria

67. http://en.wikipedia.org/wiki/Sargassum

68. http://www.taipeitimes.com/News/taiwan/archives/2008/01/12/2003396760

69. http://en.wikipedia.org/wiki/Pleurochrysis_carterae

70. lyovo GD, Du G, Chen J (2010) Sustainable Bioenergy Bioprocessing Biomethane Production, Digestate as Biofertilizer and as Supplemental Feed in Algae Cultivation to Promote Algae Biofuel Commercialization. J Microbial Biochem Technol 2: 100-106.

71. Erzheng Su, Pengyong You, Dongzhi Wei (2009) In situ lipase catalyzed reactive extraction of oilseeds with short-chained dialkyl carbonates for biodiesel production. J Bioresource Technology 100: 5813-5817

72. http://en.wikipedia.org/wiki/Palm_oi

73. Karanam SK, Medicherla NR (2010) Application of Doehlert experimental design for the optimization of medium constituents for the production of L-asparaginase from Palm Kernal cake (Elaeis guineensis). J Microbial Biochem Technol 2: 7-12.

74. Imandi SB, Karanam SK, Garapati HR (2010) Optimization of Proces Parameters for the Productionof Lipase in Solid State Fermentation by Yarrowia lipolytica from Niger Seed oil Cake (Guizotia Abyssinica). J Microbial Biochem Technol 2: 28-33.

75. De Lima CJB, Coelho LF, da Silva GP, Alvarez G, Contiero J (2010) L(+) Lactic Acid Production by New Lactobacillus Rhamnosus B 103. J Microbial Biochem Technol 2: 64-69.

76. http://www.mendeley.com/research/enzymatic-deconstruction-of-xylan-forbiofuel-production/

77. Daisy A (2011) The Impact and Treatment of Night Soil in Anaerobic Digester: A Review. J Microbial Biochem Technol 3: 43-50

78. Dajanta K, Apichartsrangkoon A, Chukeatirote E (2011) Antioxidant properties and total phenolics of thua nao (a Thai fermented soybean) as affected by Bacillus-fermentation. J Microbial Biochem Technol 3: 56-59.

79. David Pimentel, Tad W Patzek (2005) Ethanol Production Using Corn Switchgrass, and Wood; Biodiesel Production Using Soybean and Sunflower Natural Resources Research 14: 65-76

80. WH (Emile) van Zyl, Riaan den Haan, Daniel C la Grange, Shaunita HR, John EM Development of cellulolytic yeasts for one-step conversion of cellulosics to bioethanol 107. 